\section{REDUCED COMPLEMENT ACTIVATION AND IMPROVED POSTOPERATIVE PERFORMANCE AFTER CARDIOPULMONARY BYPASS WITH HEPARIN- COATED CIRCUITS}

A randomized controlled trial that involved 30 patients undergoing elective coronary artery bypass grafting was done to determine the effect of heparin-coated circuits and full heparinization on complement activation, neutrophil-mediated inflammatory response, and postoperative clinical recovery. Peak concentrations of terminal complement complex were $\mathbf{3 8 \%}$ lower $(p=0.004)$ in 15 patients treated with heparin-coated circuits (median $775 \mu \mathrm{g} / \mathrm{L}$, interquartile range 600 to 996) compared with those in 15 patients treated with uncoated circuits (median $1249 \mu \mathrm{g} / \mathrm{L}$, interquartile range 988 to 1443). Although no significant intergroup differences in concentrations of polymorphonuclear neutrophil elastase were found, a positive correlation $\left(r_{s}=0.74, p<0.0007\right)$ was calculated between peak concentrations of terminal complement complex and polymorphonuclear neutrophil elastase. Differences in patient recovery were analyzed with use of a score composed of fluid balance, postoperative intubation time, and the difference between rectal temperature and skin temperature. The score was significantly lower in patients treated with heparin-coated circuits $\phi=$ 0.03), whereas its components showed no intergroup significance. We conclude that the use of heparin-coated circuits with full systemic heparinization results in improved biocompatibility, as assessed by complement activation, and leads to an improved postoperative recovery of the patient. (J Thorac Cardovasc Surg 1995;110:829-34)

Piet G. M. Jansen, MD, PhD, ${ }^{a}$ Henk te Velthuis, PhD, ${ }^{a}$

Rien A. J. M. Huybregts, MD, ${ }^{a}$ Reginald Paulus, CP, ${ }^{a}$ Eisso R. Bulder, MD, Hans I. van der Spoel, MD, ${ }^{c}$ P. Dick Bezemer, $\mathrm{PhD},{ }^{d}$ Ed H. Slaats, $\mathrm{PhD},{ }^{e}$ León Eijsman, MD, PhD, ${ }^{a}$ and Charles R. H. Wildevuur, MD, PhD, ${ }^{a}$ Amsterdam, The Netherlands
$T_{\mathrm{cos}}^{\mathrm{h}}$ he use of extracorporeal circulation circuits still contributes to the morbidity of cardiac operations. Exposure of blood to the artificial surfaces of the extracorporeal circuit during cardiopulmonary bypass (CPB) results in plasmatic and cellular activation of the host defense mechanism. ${ }^{1}$ Activation of the complement cascade during CPB takes place

From the Center for Cardiopulmonary Surgery Amsterdam, ${ }^{a}$ the Departments of Anesthesiology, ${ }^{b}$ Surgical Intensive Care, ${ }^{c}$ and Biostatistics, ${ }^{\text {d }}$ Free University Hospital, Amsterdam, and Department of Clinical Chemistry, ${ }^{e}$ Onze Lieve Vrouwe Gasthuis, Amsterdam, The Netherlands.

Supported in part by Bentley Laboratories Europe BV, Uden, The Netherlands.

Received for publication July 25, 1994.

Accepted for publication Dec. 23, 1994.

Address for reprints: P. G. M. Jansen, MD, PhD, Department of Cardiac Surgery-L322, Free University Hospital, P.O. Box 7057, $1007 \mathrm{MB}$ Amsterdam, The Netherlands.

Copyright $\mathbb{C} 1995$ by Mosby-Year Book, Inc.

$0022-5223 / 95 \$ 5.00+0 \quad \mathbf{1 2 / 1 / 6 3 3 4 3}$ predominantly through the alternative pathway and results in activation of $\mathrm{C} 3$, which in turn generates an amplifying C3 convertase complex. ${ }^{2,3}$ These enzymatic complexes activate the terminal complement pathway with the formation of C5a and C5b-9 or terminal complement complex (TCC). Deposition of pore-forming TCC on erythrocytes during CPB has been associated with hemolysis and bondage of TCC on granulocytes may result in activation of the latter. ${ }^{4}$ Clinical studies have shown that the morbidity and the occurrence of adverse events of $\mathrm{CPB}$ are associated with the degree of complement activation. ${ }^{5,6}$ In this regard, it has been suggested that the biocompatibility of extracorporeal circuits be assessed by the degree of complement activation, specifically TCC. ${ }^{7,8}$

Heparin surface-coating of CPB circuits was originally introduced to enable reduction or even elimination of systemic heparinization. With strict regulations to prevent low-flow areas in the circuit, low-dose heparinization has been practiced safely 
for specific indications with significant reductions of blood loss and blood requirements. ${ }^{9}$ Several clinical studies have demonstrated reduced complement activation and lower levels of inflammatory mediators in patients treated with reduced systemic heparinization and heparin-coated circuits. ${ }^{10-13}$ However, these studies did not report on improvements in the postoperative clinical recovery of the patients associated with a clear reduction in inflammatory mediators, which should be essential in the assessment of improved biocompatibility.

The aim of this study was to determine whether the use of heparin-coated circuits and full systemic heparinization improves the biocompatibility of the circuit with respect to reduced complement activation during CPB and whether this reduction corresponds with a reduction in leukocyte-mediated inflammatory response and an improved postoperative clinical recovery. Therefore we measured plasma levels of TCC and polymorphonuclear neutrophil elastase (PMN elastase) during and after CPB. To quantitate the postoperative clinical recovery a carefully chosen score was used. This score is composed of a combination of clinical parameters representing the inflammatory response in the intensive care unit (ICU): the rectal and peripheral skin temperature, the fluid balance, and the intubation time.

\section{Patients and methods}

Design of the study. A standardized group of $30 \mathrm{pa}-$ tients undergoing elective first-time coronary artery bypass grafting (CABG) was studied to minimize interfering sources of blood activation. When significant changes can be determined in such a low-risk population, a more pronounced effect might be expected in patients with high-risk conditions undergoing CPB. Inclusion criteria were left ventricular end-diastolic pressure less than 25 $\mathrm{mm} \mathrm{Hg}$ and acetylsalicylic acid stopped for more than 3 days. Patients with preoperative coagulopathy or impaired organ function other than myocardial ischemia and those receiving antiinflammatory drugs were excluded. The patients were randomly allocated to be treated with either a heparin-coated circuit $(n=15)$ or an uncoated circuit $(n=15)$. Physicians involved in patient care and biochemists were blinded for randomization. Informed consent was obtained from each patient and the study was approved by the Medical Ethics Committee of the Free University Hospital.

Anesthesia and CPB. On the morning of the operation, patients received their usual early-morning dose of antianginal medication and lorazepam $5 \mathrm{mg}$. Anesthesia was induced with intravenous sufentanil citrate $3 \mu \mathrm{g} / \mathrm{kg}$, pancuronium bromide $0.1 \mathrm{mg} / \mathrm{kg}$, and midazolam $0.1 \mathrm{mg} / \mathrm{kg}$ and maintained by supplemental doses of these drugs. Cefuroxime $1500 \mathrm{mg}$ was given intravenously for infection prophylaxis. After endotracheal intubation, patients received mechanical ventilation of the lungs to normocapnia with an oxygen and air mixture. Radial artery and thermodilution pulmonary artery catheters were placed for hemodynamic measurements and procurement of blood samples.

The extracorporeal circulation circuit consisted of a soft-shell venous reservoir, roller pump, membrane oxygenator (Univox, Baxter Healthcare Corp., Irvine, Calif.), arterial line filter, cardiotomy reservoir, and polyvinyl tubing system. In the heparin-coated group, all parts of the extracorporeal circuit were treated with surfacebonded heparin (Duraflo II, Baxter). The total priming volume of the system was $1400 \mathrm{ml}$ and consisted of 1250 ml lactated Ringer's solution, $100 \mathrm{ml} 20 \%$ mannitol, $50 \mathrm{ml}$ $8.4 \%$ sodium bicarbonate, and 5000 IE heparin. For the performance of subtotal $\mathrm{CPB}$, a standard cannulation technique was used with cannulas placed in the ascending aorta and right atrium (two-stage venous cannula). After systemic heparinization (300 IU/kg) was accomplished, CPB was initiated when the activated clotting time was longer than 400 seconds. The left ventricle was vented via the aortic root. Blood from the pericardial cavity was collected in a cardiotomy reservoir and returned to the patient. The hematocrit value during CPB was maintained at $22 \%$ to $23 \%$; if possible, autologous blood was taken from the patient from the venous cannula just before the onset of extracorporeal circulation. A nonpulsatile flow rate was maintained at 2.2 to $2.4 \mathrm{~L} \cdot \mathrm{min}^{-1} \cdot \mathrm{m}^{-2}$ and patients were cooled to $29^{\circ}$ to $30^{\circ} \mathrm{C}$ nasopharyngeal temperature. After the aorta was crossclamped, all patients received high-potassium $(16 \mathrm{mmol} / \mathrm{L})$, cold crystalloid cardioplegic solution $\left(800\right.$ to $\left.1000 \mathrm{ml}, 4^{\circ} \mathrm{C}\right)$ for myocardial protection. Distal anastomoses of the grafts were placed during aortic crossclamping, and proximal anastomoses were constructed after aortic crossclamp release and restored mechanical ventilation. Acid-base balance was managed according to the alpha-stat concept. Patients were weaned from CPB with the use of inotropic support if necessary. After termination of CPB, heparin was neutralized by an equal dose of protamine sulfate ( 3 $\mathrm{mg} / \mathrm{kg}$ ). Autologous blood and residual volume from the extracorporeal circuit were infused in the patient as first-choice fluid administration.

Postoperative care. After the operation, all patients were transferred to the ICU, where they were treated according to a standardized protocol. Hemodynamic goals were heart rate 70 to 80 beats $/ \mathrm{min}$, mean arterial blood pressure 65 to $80 \mathrm{~mm} \mathrm{Hg}$, pulmonary artery wedge pressure 8 to $12 \mathrm{~mm} \mathrm{Hg}$, and cardiac index greater than $2.5 \mathrm{~L} \cdot \mathrm{min}^{-1} \cdot \mathrm{m}^{-2}$. The use of inotropic support was guided by the individual status of the patient. The fluid balance, the rectal temperature, and the peripheral temperature (measured on the back of the foot) were recorded every hour. The peripheral circulation was considered to be adequate if the difference between rectal temperature and peripheral skin temperature $(\Delta \mathrm{T})$ was less than $5^{\circ} \mathrm{C}$.

Patients received mechanical ventilation to normocapnia and an arterial oxygen tension greater than $80 \mathrm{~mm} \mathrm{Hg}$ with intermittent positive-pressure breathing and $5 \mathrm{~cm}$ $\mathrm{H}_{2} \mathrm{O}$ positive end-expiratory pressure. Detubation was 
Table I. Patient characteristics and surgical data

\begin{tabular}{lcc}
\hline & $\begin{array}{c}\text { Uncoated } \\
\text { circuits } \\
(n=15)\end{array}$ & $\begin{array}{c}\text { Heparin-coated } \\
\text { circuits } \\
(n=15)\end{array}$ \\
\hline Age $(\mathrm{yr})$ & $58 \pm 2$ & $60 \pm 2$ \\
Male/female & $11 / 4$ & $12 / 3$ \\
BSA $\left(\mathrm{m}^{2}\right)$ & $2.02 \pm 0.04$ & $1.99 \pm 0.05$ \\
LVEDP $(\mathrm{mm} \mathrm{Hg})$ & $15 \pm 1$ & $14 \pm 0.2$ \\
Total heparin $(\mathrm{mg} / \mathrm{kg})$ & $6.1 \pm 0.1$ & $6.0 \pm 0.1$ \\
Total protamine $(\mathrm{mg} / \mathrm{kg})$ & $6.1 \pm 0.1$ & $6.0 \pm 0.1$ \\
CPB time (min) & $100 \pm 8$ & $107 \pm 6$ \\
Distal anastomoses & $4(2-6)$ & $3(1-6)$
\end{tabular}

There were no significant differences between groups. Distal anastomoses are presented as median with range. The internal mammary artery was used in 11 patients in the uncoated group and in 13 patients in the heparin-coated group. $B S A$, Body surface area, $L V E D P$, left ventricular end-diastolic pressure; $C P B$ time, duration of $C P B$.

permitted if the following criteria were met: (1) the patient was awake and cooperative with a spontaneous respiration frequency 10 to $20 \mathrm{breaths} / \mathrm{min}$, (2) positivepressure support was less than $5 \mathrm{~cm} \mathrm{H}_{2} \mathrm{O}$, (3) arterial oxygen tension was greater than $80 \mathrm{~mm} \mathrm{Hg}$, and (4) inspired oxygen fraction was less than $40 \%$. The minimum required postoperative intubation time, that is, the moment that all four criteria were fulfilled, was recorded and was independent of the medical decision to detubate the patient at that time.

Basic intravenous fluid administration consisted of $\mathrm{NaCl} 0.9 \%$. Modified fluid gelatin $4 \%$ (Netherlands Production Laboratory Blood Transfusion Requirements and Infusions, Emmer Compascuum, The Netherlands) and human albumin $20 \%$ (Central Laboratory Netherlands Red Cross Blood Transfusion Service, Amsterdam, The Netherlands) were added when the colloid oncotic pressure was less than $15 \mathrm{~mm} \mathrm{Hg}$. Packed red blood cells were infused when the hematocrit level was less than $26 \%$. Blood loss and blood requirements were recorded until 18 hours after the operation.

Blood sampling and processing. All blood samples were drawn from the radial artery catheter or the arterial site of the extracorporeal circulation circuit distal from the arterial line filter and immediately immersed in crushed ice. After platelet-poor plasma was prepared, samples were stored at $-70^{\circ} \mathrm{C}$. Hematocrit value, leukocyte counts, and platelet counts were determined from all samples. Concentrations of TCC and PMN elastase were not corrected for dilution.

Terminal complement complex. Two milliliters of blood was collected in tubes and anticoagulated with ethylenedinitrotetra acetate before induction of anesthesia (baseline), after aortic crossclamp release, after termination of $\mathrm{CPB}$, and 20 minutes after protamine infusion. Fluid phase C5b-9 complement complex concentrations were determined with use of an enzyme immunoassay according to protocol (Behringwerke AG Diagnostica, Marburg, Germany).

$P M N$ elastase. Two milliliters of blood was collected in tubes and anticoagulated with citrate before induction of anesthesia (baseline), after aortic crossclamp release, after termination of $\mathrm{CPB}$, and 1 hour after patient arrival

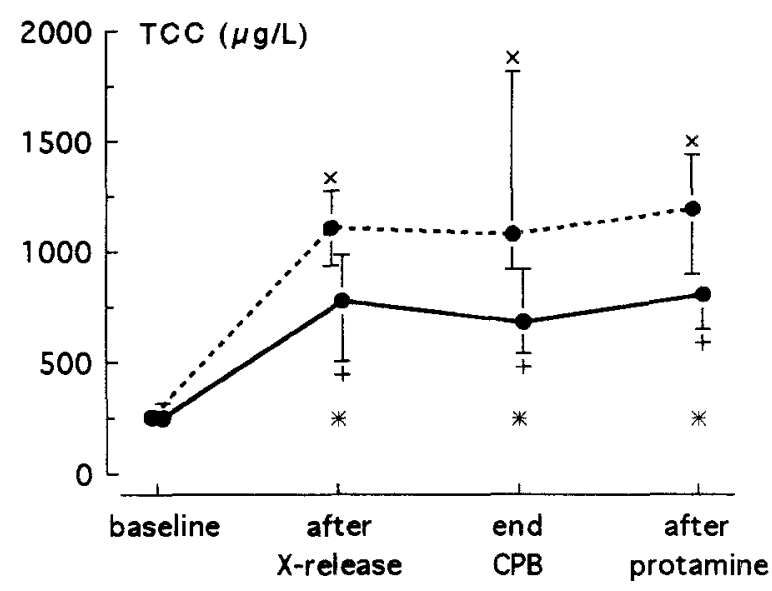

Fig. 1. Concentrations of fluid-phase TCC in patients treated with uncoated circuits (dotted line) or heparincoated circuits (solid line). Data presented as medians with interquartile range. $X$-release, crossclamp release; ${ }^{*} p<0.05$ between groups; ${ }^{\times} p<0.005$ compared with baseline values; ${ }^{+} p<0.05$ compared with baseline values.

in the ICU. PMN elastase concentrations were determined with use of an activating immunization method (Merck Diagnostica, Darmstadt, Germany) with an automated homogenous enzyme immunoassay (Hitachi 717 selective analyzer, Boehringer, Mannheim, Germany).

Data analysis. Data were stored and analyzed with the use of standard computer software (Statview 4.02, Abacus Concepts, Berkeley, Calif.). To quantitate the inflammatory response, a face validity-based score was applied. ${ }^{14}$ This "clinical performance score" is composed of the sum of (1) the total fluid balance until 18 hours after operation (measured during the operation and every hour in the ICU), (2) the mean $\Delta \mathrm{T}$ during the first 18 hours in the ICU (measured every 2 hours), and (3) time of fulfillment of detubation criteria divided by 4 . In this way, all the components of the score have a comparable range and therefore a comparable weight in the score. A higher score indicates a more pronounced inflammatory response.

Comparisons between groups were assessed with unpaired two-tailed $t$ tests. Nonparametric statistical methods were used to analyze the skewed biochemical data (TCC and PMN elastase): comparisons within groups were assessed with the Wilcoxon signed-rank test and comparisons between groups with the Mann-Whitney U test. Spearman's rank correlation $\left(r_{s}\right)$ was calculated when appropriate. A two-tailed $p$ value $<0.05$ was considered to be statistically significant. Means plus or minus the standard error of the mean are presented, unless otherwise stated.

\section{Results}

Demographic data and surgical data of both groups are listed in Table I. No complications occurred and all patients survived and were dis- 


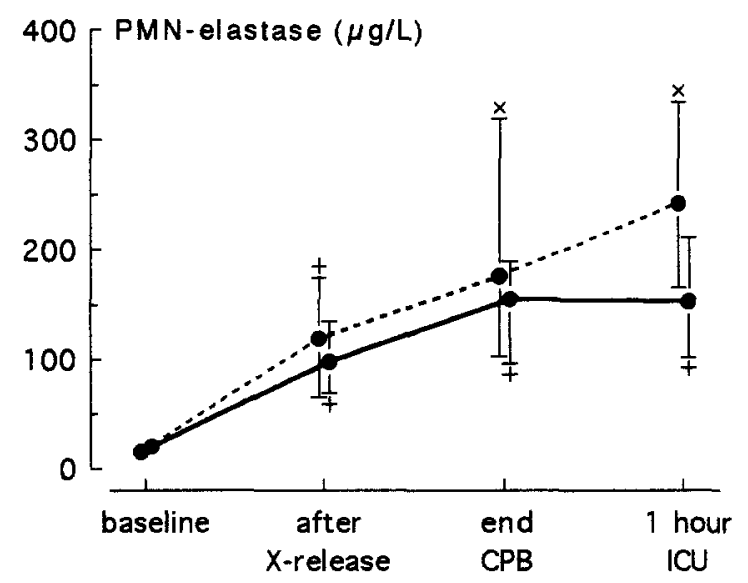

Fig. 2. Concentrations of PMN elastase in patients treated with uncoated circuits (dotted line) or heparincoated circuits (solid line). Data presented as medians with interquartile range. There were no differences between groups at distinct sample moments. $X$-release, Crossclamp release; ${ }^{\times} p<0.005$ compared with baseline values; ${ }^{+} p<0.05$ compared with baseline values.

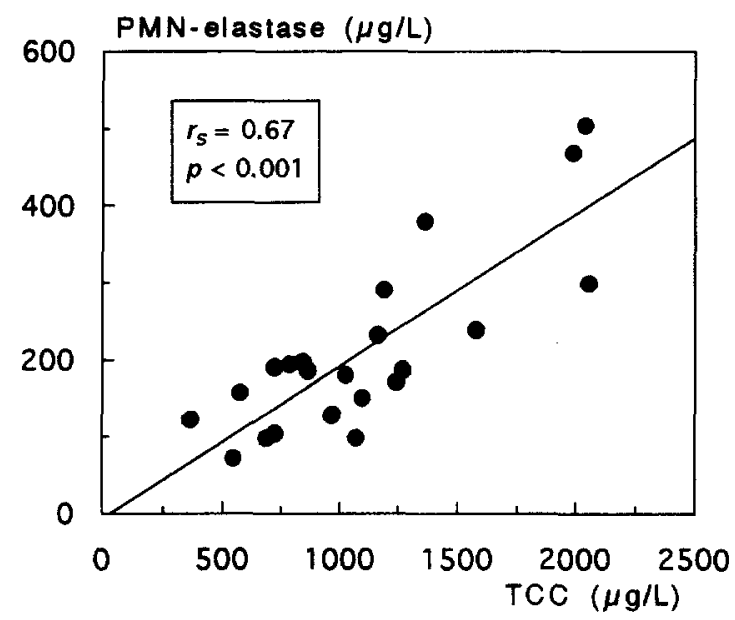

Fig. 3. Scatter diagram of pooled data of post-CPB peak levels of fluid-phase TCC and post-CPB peak levels of PMN elastase.

charged from the ICU on the first postoperative day. Both groups demonstrated a significant increase in circulating levels of TCC during and after CPB compared with baseline values (Fig. 1), but no further increments were observed after administration of protamine. Post-CPB peak levels of TCC were $38 \%$ lower in the heparin-coated group (775 $\mu \mathrm{g} / \mathrm{L}$, interquartile range 600 to 996) compared with those in the uncoated group $(1249 \mu \mathrm{g} / \mathrm{L}$, interquartile range 988 to $1443, p=0.004)$. In both groups,

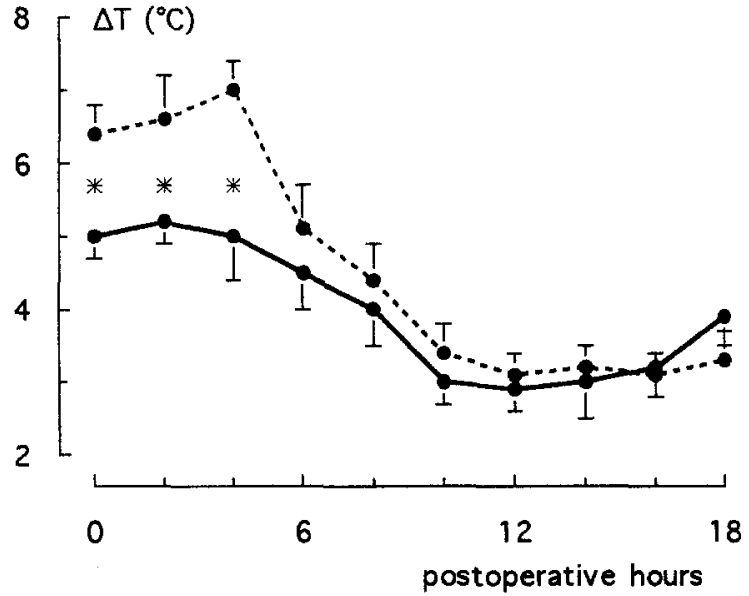

Fig. 4. Difference between rectal temperature and peripheral skin temperature $(\Delta T)$ measured during first 18 hours after operation in patients treated with uncoated circuits (dotted line) or heparin-coated circuits (solid line). Data presented as means plus or minus standard error of mean. ${ }^{*} p<0.05$ between groups.

concentrations of PMN elastase were significantly higher at the end of CPB compared with baseline values (Fig. 2). Concentrations of PMN elastase tended to be higher in the uncoated group, with the greatest difference occurring during the ICU stay $(p=0.07)$. A positive correlation was found between post-CPB peak levels of TCC and PMN elastase (Fig. 3, $r_{s}=0.74, p=0.0007$ ).

The course of $\Delta \mathrm{T}$ is presented in Fig. 4. During the first 4 hours in the ICU, $\Delta \mathrm{T}$ was significantly higher in the uncoated group, and another 4 hours later $\Delta \mathrm{T}$ was less than the desired $5^{\circ} \mathrm{C}$ in both groups. The clinical performance score and its components are depicted in Table II. A lower score ( $p=$ 0.03 ) was calculated for the heparin-coated group, whereas none of the components were different among groups. There were no differences between groups with respect to postoperative blood loss, blood requirements, hematocrit value, leukocyte count, or platelet count. Neither hemodynamic variables nor gas exchange values yielded intergroup differences. The hemodynamic response to CPB was not influenced by protamine infusion.

\section{Discussion}

This study clearly demonstrated that the use of heparin-coated circuits resulted in reduced concentrations of TCC during elective first-time CABG with normal heparinization. Moreover, the reduction of complement activation corresponded with 
improved postoperative recovery, as represented by a favorable clinical performance score in patients treated with heparin-coated circuits.

In all patients significant increments in circulating TCC were observed, but at all sample points during and after CPB concentrations of TCC were significantly lower in patients treated with heparin-coated circuits. Additional activation of the complement cascade by heparin-protamine complexes, as observed by others, ${ }^{15,16}$ was not reflected in further increments of TCC levels after protamine infusion.

Because we have solely incorporated measurements of the terminal complex of complement activation, the mechanism by which the lower concentrations of TCC with heparin-coated circuits occurred remains to be elucidated. Both surfacebound and fluid-phase heparin exhibit inhibitory interference with multiple steps in the complement cascade. ${ }^{17}$ The inactivation of $\mathrm{C} 3 \mathrm{~b}$ is intensified by heparin, ${ }^{18}$ and Maillet and associates ${ }^{19}$ postulated that heparin prevents the generation of the $\mathrm{C} 3$ amplification convertase. Apart from the inhibitory capacity of heparin on activation of the alternative pathway, the lower TCC concentrations also might be explained by direct binding of TCC to the heparin coating, as proposed by Videm and associates ${ }^{20}$ on the basis of in vitro studies.

So far, complement studies that demonstrated a reduction of TCC with heparin-coated circuits were done in patients treated with reduced systemic heparinization in combination with heparin coating. ${ }^{10,12,13}$ Because complement activation is inhibited by both surface-bound and fluid-phase heparin, no conclusions can be made concerning an inhibitory effect on complement activation of heparin coating and reduced systemic heparinization in comparison with routine heparinization and uncoated circuits. In the study presented here, an identical systemic heparinization protocol ( $3 \mathrm{mg} / \mathrm{kg}$ ) for both heparin-coated and uncoated circuits was used, and clearly the inhibitory effect of heparin coating as the one discriminating variable on complement activation could be determined. This means that in a routine setting of $\mathrm{CABG}$ with full heparinization, a reduction of complement activation can be obtained when heparin-coated circuits are applied.

The diversity of inflammatory mediators identified in connection with CPB makes it difficult to determine their interaction or to define their role in the inflammatory response. Although an inhibitory effect of heparin-coated circuits on neutrophil activation could not be determined here, we
Table II. Clinical performance score

\begin{tabular}{lrrr}
\hline & $\begin{array}{c}\text { Uncoated } \\
\text { circuits } \\
(n=15)\end{array}$ & $\begin{array}{c}\text { Heparin-coated } \\
\text { circuits } \\
(n=15)\end{array}$ & $p$ Value \\
\hline (1) Fluid balance (L) & $3.0 \pm 0.4$ & $2.4 \pm 0.3$ & 0.24 \\
(2) Extubation criteria (hr) & $20.0 \pm 2.1$ & $17.4 \pm 1.2$ & 0.30 \\
(3) Mean $\Delta \mathrm{T}\left({ }^{\circ} \mathrm{C}\right)$ & $4.6 \pm 0.2$ & $4.0 \pm 0.3$ & 0.12 \\
Clinical performance score & $12.6 \pm 0.8$ & $10.7 \pm 0.4$ & 0.03 \\
\hline
\end{tabular}

Clinical performance score $=(1)+(2) / 4+(3) \cdot p$ Value denotes intergroup level of significance. Mean $\Delta \mathrm{T}=$ mean difference between rectal and peripheral skin temperature in the ICU, measured every 2 hours until 18 hours after operation.

demonstrated that $55 \%$ of the increase in PMN elastase could be explained by the increase in TCC. This is in agreement with previous findings that complement activation can up-regulate neutrophils. ${ }^{21-23}$

Biocompatibility is defined as the ability of biomaterials to perform without a host response and usually is expressed by the levels of bioactive substances encountered in the circulation after contact with the biomaterial. However, the clinical response to improved biocompatibility is difficult to assess in patients undergoing elective CABG, because these responses are usually mild. Instead of isolated clinical parameters, we propose the use of a scoring system as a clinical end point. The score is composed of three parameters with equal weight, all more or less related with an inflammatory response to CPB. The fluid balance might reflect edema formation, whereas the difference between rectal temperature and skin temperature represents the peripheral circulation. The actual moment of detubation is merely a medical decision and is likely to flaw the score system. For that reason, we chose to record the moment at which standardized criteria for detubation are fulfilled. The lower score of patients treated with heparin-coated circuits indicates that, even after low-risk CABG, the postoperative inflammatory response was attenuated. The difference between rectal temperature and skin temperature was significantly higher in patients treated with uncoated circuits until 6 hours after operation. After that time, $\Delta \mathrm{T}$ reached levels equal to those of the heparin-coating group. Early recovery of $\Delta \mathrm{T}$, as was observed in the heparin-coated group, might be particularly beneficial in patients with a compromised peripheral circulation.

In conclusion, we demonstrated that the biocompatibility of extracorporeal circulation circuits, as assessed by complement activation, can be improved 
by the immobilization of heparin on the inner surface of these circuits. A favorable clinical performance score was observed in patients treated with heparin-coated circuits. The potential usefulness and clinical relevance of heparin-coated circuits might be greatest when they are incorporated in protocols dealing with early recovery and reduction of intensive care requirements after cardiac operations, specifically in patients with high-risk factors.

\section{REFERENCES}

1. Butler J, Rocker GM, Westaby S. Inflammatory response to cardiopulmonary bypass. Ann Thorac Surg 1993;55:552-9.

2. Chenoweth DE, Cooper SW, Hugli TE, Steward RW, Blackstone EH, Kirklin JW. Complement activation during cardiopulmonary bypass: evidence for generation of C3a and C5a anaphylatoxins. N Engl J Med 1981;304:497-503.

3. van Oeveren W, Kazatchkine MD, DeschampsLatscha B, et al. Deleterious effect of cardiopulmonary bypass. J Thorac Cardiovasc Surg 1985;89: 888-99.

4. Salama A, Hugo F, Heinrich D, et al. Deposition of terminal C5b-9 complement complexes on erythrocytes and leukocytes during cardiopulmonary bypass. N Engl J Med 1988;318:408-14.

5. Kirklin JK, Westaby S, Blackstone EH, Kirklin JW, Chenoweth DE, Pacifico AD. Complement and the damaging effects of cardiopulmonary bypass. J THORAC CARDIOVASC SURG 1983;86:845-57.

6. Moore FD, Warner KG, Assousa S, Valeri CR, Khuri SF. The effects of complement activation during cardiopulmonary bypass. Ann Surg 1988;208:95-103.

7. Deppisch R, Schmitt V, Bommer J, Hansch GM, Ritz $\mathrm{E}$, Rautenberg EW. Fluid phase generation of terminal complement complex as a novel index of bioincompatibility. Kidney Int 1990;37:696-706.

8. Mollnes TE, Videm V, Riesenfeld J, et al. Complement activation and bioincompatibility: the terminal complement complex for evaluation, and surface modification with heparin for improvement of biomaterials. Clin Exp Immunol 1991;88(suppl 1):21-6.

9. von Segesser LK, Wiess BM, Garcia E, Gallino A, Turina M. Reduced blood loss and transfusion requirements with low systemic heparinization: preliminary clinical results in coronary artery revascularization. Eur J Cardiothorac Surg 1990;4:639-43.

10. Videm V, Svennevig JL, Fosse E, Semb G, Østerud A, Mollnes TE. Reduced complement activation with heparin-coated oxygenator and tubings in coronary bypass operations. J THORAC CARDIOVASC SuRg 1992; 103:806-13.
11. Borowiec J, Thelin S, Bagge L, Nillson L, Venge P, Hansson HE. Heparin-coated circuits reduce activation of granulocytes during cardiopulmonary bypass. J Thorac Cardiovasc Surg 1992;104:642-7.

12. Pekna M, Hagman L, Haldén E, Nilsson UR, Nilsson $\mathrm{B}$, Thelin S. Complement activation during cardiopulmonary bypass: effects of immobilized heparin. Ann Thorac Surg 1994;58:421-4.

13. Fosse E, Moen O, Johnson E, et al. Reduced complement and granulocyte activation with heparincoated cardiopulmonary bypass. Ann Thorac Surg 1994;58:472-7.

14. Feinstein AR. The evaluation of validity. In: Feinstein AR. Clinimetrics. 1st ed. New Haven and London: Yale University Press, 1987:141-66.

15. Cavarocchi NC, Schaff HV, Orszulak TA, Homburger HA, Schnell WA, Pluth JR. Evidence for complement activation by protamine-heparin interaction after cardiopulmonary bypass. Surgery 1985;98:525-30.

16. Kirklin JK, Chenoweth DE, Naftel DC, et al. Effects of protamine administration after cardiopulmonary bypass on complement, blood elements, and the hemodynamic state. Ann Thorac Surg 1986;41:193-9.

17. Kazatchkine MD, Fearon DT, Metcalfe DD, Rosenberg RD, Austen KF. Structural determinants of the capacity of heparin to inhibit the formation of the human amplification C3 convertase. J Clin Invest 1981;67:223-8.

18. Boackle RJ, Caughman GB, Vesely J, Medgyeshi G, Fudenberg HH. Potentiation of factor $\mathrm{H}$ by heparin: a rate-limiting mechanism for inhibition of the alternative complement pathway. Mol Immunol 1983;20: 1157-64.

19. Maillet F, Kazatchkine MD, Glotz D, Fischer E, Rowe M. Heparin prevents formation of the human $\mathrm{C} 3$ amplification convertase by inhibiting the binding site for B on C3b. Mol Immunol 1983;20:1401-4.

20. Videm V, Mollnes TE, Garred P, Svennevig JL. Biocompatibility of extracorporeal circulation: in vitro comparison of heparin-coated and uncoated oxygenator circuits. J Thorac CARdiovasc Surg 1991;101: 654-60.

21. Chenoweth DE, Erickson BW, Hugli TE. Human C5arelated synthetic peptides as neutrophil chemotactic factors. Biochem Biophys Res Commun 1979;86:227-34.

22. Gu YJ, Van Oeveren W, Akkerman C, Boonstra PW, Huyzen RJ, Wildevuur ChRH. Heparin-coated circuits reduce the inflammatory response to cardiopulmonary bypass. Ann Thorac Surg 1993;55:917-22.

23. Butler J, Pillai R, Rocker GM, Westaby MS, Parker D, Shale DJ. Effect of cardiopulmonary bypass on systemic release of neutrophil elastase and tumor necrosis factor. J Thorac CARDIOvasC SURG 1993;105:25-30. 